\title{
Replacing the nitrogen nutrition index by the chlorophyll meter to assess wheat $\mathbf{N}$ status
}

\author{
Lorène PROST*, Marie-Hélène JEUfFroY \\ INRA, UMR211, INRA/INA P-G, 78850 Thiverval-Grignon, France
}

(Accepted 26 July 2007)

\begin{abstract}
The performance of cultivars is strongly linked to the growing conditions that vary according to both controlled and uncontrolled experimental factors. Specifically, there is a need to control the efficiency of $\mathrm{N}$ use by wheat, Triticum aestivum L., to minimize nitrogen losses and deficiency. The nitrogen nutrition index (NNI) is a precise indicator of nitrogen status but it does not suit the users' practical constraints because it requires time-consuming measurements and destructive plant sampling at a precise growth stage. Here we tested the soil plant analysis development (SPAD) chlorophyll meter as an alternative to the nitrogen nutrition index (NNI). The chlorophyll meter is a more convenient, leaf clip-on device that determines the relative amount of chlorophyll present in plant leaves. We first identified which leaf should be used; we then compared SPAD and NNI data from various experiments. We also followed SPAD measurements around flowering time to determine a common time span of measurements for all the cultivars of a trial presenting a wide range of earliness. Our results show a non-cultivar-dependent, exponential relationship between the SPAD index and NNI at flowering, with a $\mathrm{r}^{2}$ equal to 0.89 . This result implies that the SPAD chlorophyll meter can be used as an alternative to NNI to measure N status in wheat. We also showed that SPAD measurements can be taken before flowering, e.g. during heading, to characterize nitrogen status at flowering. This result provides an organizational leeway to experimenters who can then follow more precisely the N status of their trials. Thus the SPAD index is a good substitute for NNI because it is convenient to use.
\end{abstract}

plant nutrition / nitrogen / chlorophyll meter / SPAD readings / non-destructive testing

\section{INTRODUCTION}

The market of winter wheat (Triticum aestivum L.) has to deal with contradictory requirements regarding nitrogen. Whereas there are increasing requirements for high grain protein content, there is also a global search for fertilization management to maximize $\mathrm{N}$-use efficiency and minimize $\mathrm{N}$ losses linked with environmental concerns (Anjana et al., 2007). As a consequence, a better knowledge of the varietal response to various levels of nitrogen status, including deficiency, is required. Each year, many multi-environment trials are conducted to assess the behavior of recently registered cultivars in order to help growers to choose the cultivars best suited to their conditions (see van Eeuwijk, 1995 for example). These trials are subjected to a wide range of limiting factors, including nitrogen deficiency, that must be precisely described (Brancourt-Hulmel et al., 1999). The nitrogen nutrition index (NNI) obtained from the curve proposed by Justes et al. (1994) has been shown to be a precise and specific indicator to characterize the $\mathrm{N}$ status of the wheat crop throughout vegetative growth. As NNI measured at flowering (GS10-5-2 on Feekes' scale) is a good indicator of the effect of $\mathrm{N}$ deficiency on grain yield (Jeuffroy and Bouchard, 1999) and grain protein content (Justes et al., 1997), NNI is mainly used at the flowering stage to characterize the $\mathrm{N}$ status during the vegetative period. Moreover, NNI does not depend on cultivar or soil

*Corresponding author: prost@grignon.inra.fr and weather conditions (Justes et al., 1994). Yet measuring the NNI precisely at flowering is inconvenient for those responsible for cultivar assessment, such as plant breeders, advisers from technical institutes or various advisory services and people responsible for registering cultivars in the French or European Catalogue of Agricultural Species. Firstly, it requires destructive plant sampling on a given area in order to measure the aerial biomass of the crop and an analysis of the nitrogen content of this biomass. Secondly, the sampling must be done at precisely the flowering stage. However, in cultivar trials, the time span between the flowering stages of the earliest and the latest varieties varies between two and three weeks (GEVES, Pers. com.), necessitating several sampling visits. Moreover, the people in charge of these trials usually visit their trials to record heading (GS 10-3) and do not come back at flowering. Thus, although NNI is very reliable, it is rarely used because it is time-consuming and expensive.

Our objective is to propose another method to assess the $\mathrm{N}$ status of crops that suits the practices of the potential users. Several studies, reviewed by Debaeke et al. (2006), for example, have shown that leaf chlorophyll content could be used to diagnose the nitrogen status of plants. Indirect measurements of leaf chlorophyll content can be made with the Minolta SPAD meter (Soil Plant Analysis Development, Minolta Camera Co., Osaka, Japan), a hand-held spectrophotometer whose readings are instantaneous and involve no destructive sampling. SPAD readings have proven to be positively correlated 
with leaf $\mathrm{N}$ content for different species and at various growth stages. Peng et al. (1993) have shown a positive correlation between leaf $\mathrm{N}$ content and SPAD readings at various growth stages for rice (Oryza sativa L.), as done by Wood et al. (1992) or Schepers et al. (1992) for corn (Zea Mays L.), or by Reeves et al. (1993) for winter wheat (Triticum aestivum L.). As a consequence, the SPAD meter has been recognized as a tool to detect $\mathrm{N}$ deficiencies and monitor $\mathrm{N}$ status; for example, by comparing the SPAD readings of any treatment with those of a fully N-fertilized treatment (Blackmer and Schepers, 1995; Varvel et al., 1997; Vidal et al., 1999).

But replacing NNI by SPAD measurements has been little studied on wheat. Vouillot et al. (1998) have studied the relationship between SPAD and NNI of winter wheat, but at early stem elongation. Debaeke et al. (2006) have proposed a relationship at flowering, but only for durum wheat. Most relationships between SPAD readings and $\mathrm{N}$ contents have been established with the leaf $\mathrm{N}$ content and not with the wholeplant $\mathrm{N}$ content, as used for NNI.

Starting off with the practical constraints of potential users leads us to put the question of the substitution of NNI by SPAD readings differently. We can define operational specifications: if the method is to be widely used, the correlation between SPAD measurements and NNI must be independent of the cultivar and the year. In fact, Peng et al. (1993), Schepers et al. (1992), Debaeke et al. (2006) and Bavec and Bavec (2001) have pointed out that SPAD readings vary among bread wheat cultivars, and could vary among years and locations. However, many researchers have suggested using a SPAD index, i.e. the SPAD reading of the plants divided by that of fully $\mathrm{N}$-fertilized plants (Fox et al., 1994; Blackmer and Schepers, 1995; Varvel et al., 1997; Debaeke et al., 2006). The SPAD method must also be well suited to detecting nitrogen deficiencies, and be easy to use for people who do not have much time for measurement and who cannot take the measurements at the exact flowering stage of each variety.

Our study therefore had two objectives related to the use of SPAD readings to characterize the $\mathrm{N}$ nutrition of the numerous cultivars compared in cultivar trials. As a preliminary, we compared SPAD readings on leaves 1 and 2 to determine on which leaf our study should focus for the results to be the most stable. We then studied the relationship between the SPAD readings and NNI, and we particularly analyzed the effect of cultivar and year. Finally, we looked for a time span, around flowering, in which SPAD readings reflect the crop $\mathrm{N}$ status at flowering.

\section{MATERIALS AND METHODS}

\subsection{Relationship between SPAD readings and NNI}

In this part we used data from three field experiments conducted in 1998-1999, 2000-2001 and 2001-2002 on winter wheat at the Experimental Unit of the National Institute for Agricultural Research (INRA), Grignon, France $\left(48.9^{\circ} \mathrm{N}\right.$, $1.9^{\circ} \mathrm{E}, 130 \mathrm{~m}$ elevation) on a loamy soil.

\subsubsection{Experimental designs}

In 1998-1999, 5 cultivars were factorially combined with 5 fertilization strategies, making 25 treatments in a randomized block design with three replicates. The five cultivars were chosen for several reasons: Soissons was the most commonly grown cultivar in France at that time, with a high grain protein content and known sensitivity to early $\mathrm{N}$ deficiency. Baltimor is a late cultivar with variable protein content. Cockpit is resistant to $\mathrm{N}$ deficiency but with low grain protein content; Florence Aurore is a very early cultivar of first-class quality and the last, Tremie, is a productive cultivar with low protein content, widely grown in France in the nineties. Five different $\mathrm{N}$ fertilization rates were applied, aimed at creating temporary deficiencies at various stages, with various intensities and durations. The $\mathrm{N}$ treatments are described in Table I. The intensive treatment, "in", corresponds to the treatment for which nitrogen was applied to prevent nitrogen deficiency during the crop cycle. The total amount of nitrogen applied was calculated with the balance-sheet method (Machet et al., 1990) on the basis of the potential yield specific to the site, $10 \mathrm{Mg} \mathrm{ha}^{-1}$.

In 2000-2001 and 2001-2002, two similar experiments were conducted: various amounts of ammonium nitrate fertilizer were applied in three blocks (Tab. I) to create various crop $\mathrm{N}$ status conditions before flowering. Ten winter wheat cultivars differing in terms of earliness for heading and maturity, potential yield, and susceptibility to airborne diseases were used in this study. They included high-yielding cultivars with low grain protein content, such as Arche, Isengrain and Rumba, medium-yielding cultivars with medium to high grain protein content such as Camp-Rémy, DI9714, Récital, Soissons, a hybrid cultivar, Hynoprécia, and two multi-diseaseresistant cultivars, Oratorio and Renan. Further details of these experiments are given in Barbottin et al. (2005). Each of these three experiments was kept free of weeds, pests, diseases and drought stress using appropriate chemicals and irrigation.

\subsubsection{Dataset}

In the three experiments, SPAD readings and NNI measurements were taken at the precise flowering stage of each cultivar for each treatment. To calculate NNI, plant samples of $0.35 \mathrm{~m}^{2}$ were taken to measure dry matter per $\mathrm{m}^{2}$ and $\mathrm{N}$ content of the aerial parts. Then NNI was calculated as the ratio of the total N content in aerial dry matter per $\mathrm{m}^{2}$ to the critical $\mathrm{N}$ content, derived from the curve published by Justes et al. (1994) and the observed aerial biomass of the crop. Periods of $\mathrm{N}$ deficiency occurred when NNI was significantly less than 1. Details of plant sampling are given by Barbottin et al. (2005).

SPAD readings, in dimensionless units usually lying between 30 and 60, were taken on both flag leaves, L1, and second leaves, L2, just below the flag leaves, at flowering (GS 105-2). Two measurements were taken for each leaf: in the first third and in the outer two-thirds of the leaf blade. The measurements were taken on 15 randomly selected stems within each plot, giving 30 measurements for each plot and each leaf number, i.e. flag leaf and second leaf. Hence the final SPAD 
Table I. N treatments of the three experiments (1999, 2001 and 2002 in Grignon, France). Treatments are defined as nn: no nitrogen supply treatment, lw: low nitrogen supply treatment, nr: reduced nitrogen supply treatment, in: intensive nitrogen supply treatment and hn: high nitrogen supply treatment.

\begin{tabular}{|c|c|c|c|c|c|c|}
\hline \multicolumn{7}{|c|}{1999} \\
\hline \multicolumn{2}{|c|}{$1999 \mathrm{~N}$ application Date } & 11 Mar. 1999 & 6 April 1999 & 29 April 1999 & 12 May 1999 & 27 May 1999 \\
\hline \multicolumn{2}{|c|}{$\begin{array}{l}\text { Middle Feekes stage of the } \\
\text { cultivars }\end{array}$} & 3 & 5 & 7 & 10 & $10-5-2$ \\
\hline \multicolumn{2}{|c|}{$\begin{array}{ll}\begin{array}{l}\mathrm{N} \text { treatment } \\
(\mathrm{kg} / \mathrm{ha})\end{array} & \text { Total N Applied } \\
\end{array}$} & & & & & \\
\hline $\mathrm{nn}$ & 0 & - & - & - & - & - \\
\hline $1 \mathrm{w}$ & 60 & 60 & - & - & - & - \\
\hline $\mathrm{nr}$ & 120 & 60 & 60 & - & - & - \\
\hline in & 200 & - & - & 100 & - & 100 \\
\hline hn & 260 & 60 & 100 & - & 100 & - \\
\hline \multicolumn{7}{|c|}{2001} \\
\hline \multicolumn{2}{|c|}{$2001 \mathrm{~N}$ application Date } & 19 Feb. 2001 & 02 April 2001 & 02 May 2001 & 30 May 2001 & \\
\hline \multicolumn{2}{|c|}{ Middle Feekes stage } & 3 & 5 & 10 & $10-5-2$ & \\
\hline \multirow{2}{*}{\multicolumn{2}{|c|}{$\begin{array}{ll}\mathrm{N} \text { treatment } & \text { Total } N \text { Applied } \\
\end{array}$}} & & & & & \\
\hline $\mathrm{nn}$ & & - & - & - & - & \\
\hline lw & 60 & 60 & - & - & - & \\
\hline $\mathrm{nr}$ & 160 & 60 & 100 & - & - & \\
\hline in & 240 & 60 & 100 & 80 & - & \\
\hline \multirow[t]{2}{*}{ hn } & 330 & 60 & 100 & 80 & 90 & \\
\hline & & & 2002 & & & \\
\hline \multicolumn{2}{|c|}{$2002 \mathrm{~N}$ application date } & 05 Mar. 2002 & 25 Mar. 2002 & 18 April 2002 & 13 May 2002 & 30 May 2002 \\
\hline \multicolumn{2}{|c|}{ Middle Feekes stage } & 3 & 5 & 7 & 10 & $10-5-2$ \\
\hline $\mathrm{N}$ treatment & Total N Applied & & & & & \\
\hline nn & 0 & - & - & - & - & - \\
\hline $\mathrm{nr}$ & 140 & 60 & 80 & - & - & - \\
\hline in & 260 & 60 & 80 & 80 & 40 & \\
\hline $\mathrm{hn}$ & 340 & 60 & 80 & 80 & 40 & 80 \\
\hline
\end{tabular}

measurement for each treatment was the mean of 3 replicates of 30 measurements.

The SPAD index was also calculated as the ratio of the SPAD reading on one treatment to that of the most heavily fertilized treatment of the same cultivar in the same trial, i.e. hn treatment, after checking that the NNIs of these treatments were greater than 1 to confirm that they had a non-limiting nitrogen status:

SPAD index $(i, j)=\operatorname{SPAD}(i, j) / \operatorname{SPAD}$ ref $(i)$, where $i$ is the cultivar and $\mathrm{j}$ the $\mathrm{N}$ treatment.

We obtained a set of SPAD indexes between 0.459 and 1.033 with many values of 1 . In fact, the way the index was calculated, by using the SPAD reading of the most heavily fertilized treatment, meant that there was only one data value greater than 1 .

\subsubsection{Statistical analysis}

Because various leaves were used in the literature and because SPAD measurements can vary according to the leaf on which they are taken (Schepers et al., 1992), we decided to first study whether the measurements taken on different leaves were correlated. We tested the correlation between L1 and L2 SPAD readings by the CORR procedure available from
SAS/STAT (SAS Institute Inc, 1999) and the effect of year and cultivar on the relationship between L1 and L2 by means of the GLM procedure available from SAS/STAT.

All data were then fitted to the following model: $\mathrm{NNI}_{\mathrm{i}, \mathrm{j}, \mathrm{k}}=$ a. $\exp \left(\mathrm{b} . \mathrm{SPAD}_{\mathrm{i}, \mathrm{j}, \mathrm{k}}\right)$, $\mathrm{i}$ being the cultivar, $\mathrm{j}$ the year and $\mathrm{k}$ the $\mathrm{N}$ treatment, using the REG procedure available from SAS/STAT. The quality of the model was assessed with the coefficient of determination, $\mathrm{R}^{2}$, bias, root mean squared error and the relative root mean squared error, RRMSE, calculated as follows (for details, see Wallach and Goffinet, 1987; Wallach, 2006):

Bias $=\frac{1}{\text { Ndata }} \sum_{i=1}^{\text {Ndata }} Y_{i}-\hat{Y}_{i}$ where $Y_{i}$ is the measured value for situation $\mathrm{i}$ and $\hat{Y}_{i}$ is the corresponding value calculated by the model),

$$
R M S E=\sqrt{\frac{1}{\text { Ndata }} \sum_{i=1}^{\text {Ndata }}\left(Y_{i}-\hat{Y}_{i}\right)^{2}}
$$

$R R M S E=\frac{R M S E}{\bar{Y}}$ where $\bar{Y}=\frac{1}{\text { Ndata }} \sum_{i=1}^{\text {Ndata }} Y_{i}$.

To test if the cultivar and year effects were significant in this relationship, we compared the performance of the model calculated by cultivar (or by year) and the general model. The sum of the residual sums of squares for individual fit to each 
cultivar or each year ( $\Sigma \mathrm{SSi})$ was compared with the residual sum of squares for a common fit to all the cultivars and all the years $(\mathrm{SSc})$ :

$$
F=\frac{\left|S S c-\sum_{i=1}^{n} S S i\right| /((n-1) . k)}{\sum_{i=1}^{n} S S i /(N \text { data }-n k)} .
$$

The criterion F follows Fisher's law with $(\mathrm{n}-1)$. $\mathrm{k}$ and (Ndata nk) degrees of freedom. Ndata is the total number of data points, $\mathrm{n}$ is the number of individual regressions and $\mathrm{k}$ is the number of fitted parameters for each regression, equal to 2 in the case of the function chosen here.

When the models appeared to differ, we compared the RMSE of the general model with $R M S E_{n}=\sqrt{\frac{\sum_{i=1}^{n} S S i}{n}}$ of the genotypic models or of the yearly models to check which model, the general or the specific one, had the better quality.

To assess the predictive quality of the model on an independent dataset, we also calculated the root mean squared error of prediction (RMSEP) by cross-validation, whereby part of the data is used to estimate the parameters and the rest is used for validation; this procedure is repeated until each piece of data has been used either to estimate the parameters or to validate the model (See Wallach, 2006 for details).

\subsection{Time span around flowering for SPAD measurements}

In this part, we recorded SPAD readings over time in two field experiments conducted in 2004-2005 and 2005-2006 on winter wheat at the INRA Experimental Station of Grignon, France $\left(48.9^{\circ} \mathrm{N}, 1.9^{\circ} \mathrm{E}, 130 \mathrm{~m}\right.$ elevation) on a loamy soil.

\subsubsection{Experimental designs}

These two experiments combined two factors: cultivar and $\mathrm{N}$ fertilization. Three cultivars of various earliness were grown: Cezanne: heading earliness $=7.5$; Caphorn: heading earliness $=6.5$, and Vivant: heading earliness $=4.5$. Heading earliness is checked on a 1-9 scale, where 1 corresponds to the latest and 9 to the earliest. One quite extensive crop management system was applied, named CM1: the inputs were greatly decreased to maximize the gross margin for the wheat price. Compared with intensive crop management for which all inputs are calculated to avoid any limiting factors, and notably $\mathrm{N}$ deficiencies, the sowing density was $40 \%$ lower, the fertilization was reduced by $60 \mathrm{~kg} \mathrm{ha}^{-1}$ and $70 \mathrm{~kg} \mathrm{ha}^{-1}$ in 2005 and 2006, respectively, and no pesticides against pests and diseases were applied. Two $\mathrm{N}$ fertilization strategies were applied (Tab. II). For the first strategy, E, the dates of application of N fertilizer were determined according to the development stage of the earliest cultivars. In the L strategy, the dates were determined according to the crop development stage of the latest cultivars. Each treatment was replicated three times.

\subsubsection{Data collection}

On each of the three cultivars of each fertilization strategy, SPAD readings were taken every three days from 10 days before flowering to 10 days after flowering in 2005 and every day from 9 days before flowering to 8 days after flowering in 2006 (Tab. III). As in the previous trials, two measurements were taken on each of the last two leaves of 15 randomly chosen stems. Although no pesticides against pests and diseases were applied, levels of leaf diseases were very low in 2005 and 2006 and did not affect leaves enough to disturb the SPAD measurements. Plants were also sampled, according to the same protocol as in the previous experiments, in order to measure NNI at the flowering stage of each cultivar. As far as possible, the measurements were always taken at the same time of day, i.e. midday, to avoid any possible effect of this factor. In fact, it has been shown that SPAD measurements can vary according to irradiance, leaf water status and time of measurement, i.e., morning vs. afternoon (Martinez and Guiamet, 2004).

\subsubsection{Statistical analysis}

To determine the time span around flowering for which SPAD readings are still well correlated to NNI, we identified the days around flowering for which the SPAD readings were the same as those measured exactly at flowering. We expressed the dates of measurements relative to the flowering date of each cultivar in each fertilization strategy, E or L. For example, a SPAD measurement collected 9 days before flowering was encoded " -9 ". Then an analysis of variance was performed on the SPAD readings, with the date of measurement taken as a qualitative variable, using the GLM procedure available from SAS/STAT (SAS Institute Inc, 1999). Year, cultivar, fertilization strategy and replicates within a strategy were considered as fixed effect factors. The model can be written as:

$S P A D_{i j k l m}=D A T E_{i}+\operatorname{var}_{j}+N_{k}+$ rep $_{l}+$ year $_{m}+$ int + error (Model 1)

where DATE was the relative date from the flowering stage, var the cultivar ( $\mathrm{j}=1,2,3$ with Cezanne, Cap Horn, Vivant), $\mathrm{N}$ the fertilization strategy $(\mathrm{k}=1,2$ with $\mathrm{E}, \mathrm{L})$, rep the replicate $(1=1,2,3), \mathrm{m}$ the year $(\mathrm{m}=1,2$ with 2005,2006$)$ and int all the possible interactions.

Mean comparisons based on the MEANS procedure were performed to separate DATE means for which the StudentNewman-Keuls test, option SNK, indicated that significant differences existed ( $P$ below 0.05). The time span was determined as the dates on which SPAD readings were not significantly different from those at flowering, i.e. DATE " 0 " or at the closest DATE to DATE " 0 " when we had not measured the SPAD at the precise date of flowering, as happened in 2005.

\section{RESULTS AND DISCUSSION}

\subsection{Correlation between SPAD readings from different leaves}

From the first group of experiments, i.e. those of 1999, 2001 and 2002, we compared SPAD readings collected at the 
Table II. Crop treatments in the 2005 and 2006 experiments (amounts of $\mathrm{N}$ in kg/ha).

\begin{tabular}{|c|c|c|c|c|c|}
\hline \multicolumn{6}{|c|}{2005} \\
\hline $\mathrm{N}$ application Dates & & 31 Mar. 05 & 11 April 05 & 2 May 05 & 19 May 05 \\
\hline Feekes Stage & & 5 / earliest cv & 5 / latest cv & 8-9 / earliest cv & 8-9 / latest cv \\
\hline CM1 & $E$ & 60 & - & 60 & - \\
\hline & $L$ & - & 60 & - & 60 \\
\hline $\mathrm{N}$ application dates & & 10 April 06 & 20 April 06 & 15 May 06 & 23 May 06 \\
\hline Feekes Stage & & 5 / earliest cv & 5 / latest cv & 8-9 / earliest cv & 8-9 / latest cv \\
\hline Crop management & Fertilization strategy & & & & \\
\hline \multirow[t]{2}{*}{ CM1 } & $E$ & 60 & - & 60 & - \\
\hline & $L$ & - & 60 & - & 60 \\
\hline
\end{tabular}

Table III. Characteristics of the monitoring of the SPAD measurements around flowering in the 2005 and 2006 experiments.

\begin{tabular}{cccc}
\hline \multirow{2}{*}{ Year } & Cultivar & $\begin{array}{c}\text { Time span for which SPAD readings were } \\
\text { collected (in number of days from flowering, with } \\
\text { "0" flowering stage) }\end{array}$ & $\begin{array}{c}\text { Number of dates for which SPAD } \\
\text { was measured }\end{array}$ \\
\hline \multirow{2}{*}{2005} & Cezanne & $-9 /+9$ & 6 \\
\cline { 2 - 4 } & Cap Horn & $-10 /+9$ & 6 \\
\cline { 2 - 4 } & Vivant & $-9 /+9$ & 6 \\
& Cezanne & $-9 /+8$ & 18 \\
& Cap Horn & $-9 /+8$ & 18 \\
& Vivant & $-9 /+8$ & 18 \\
\hline
\end{tabular}

flowering stage on the flag leaf, SPAD L1, and the second leaf, SPAD L2. Both were highly correlated, with a correlation coefficient of 0.96 for all years and cultivars (Tab. IV). The year appeared to have no significant effect ( $P$ greater than 0.05$)$, whereas the cultivar had a significant effect on the relationship ( $P$ below $\left.10^{-4}\right)$.

On all data (Fig. 1), the relationship between SPAD L1 and SPAD L2 was the following:

$$
S P A D L 2=1.078 \times S P A D L 1-5.084 .
$$

As illustrated in Figure 1, the equation underlines the fact that SPAD L2 measurements were generally lower than SPAD L1 ones. This result was in agreement with those reviewed by Lemaire and Gastal (1997), who showed that leaf nitrogen partitioning was non-uniform within dense canopies of different species and reflected the vertical light distribution.

In the literature, no such comparison of different leaves is available. However, Schepers et al. (1992) found that variation along the length of the leaf was considerably less in an older leaf, whose collar was exposed. Matsunaka et al. (1997) also recommended using the second leaf in spite of contradictory arguments: they showed that it might begin to senesce at flowering, with complex consequences, but that its use was preferable to that of the flag leaf to predict the $\mathrm{N}$ content and that its color was more stable than that of the flag leaf. Avoiding sources of variation is a reason for preferring the second
Table IV. Correlation coefficients between flag leaf (L1) and second leaf (L2) SPAD readings for all data, then for each year and each cultivar: every correlation was significant $(P \leq 0.01)$.

\begin{tabular}{lcc}
\hline & Data (number) & Correlation coef \\
\hline All data & $(88)$ & 0.96 \\
\hline Years & $1999(25)$ & 0.96 \\
\cline { 2 - 3 } & $2001(36)$ & 0.95 \\
\cline { 2 - 3 } Cultivars & Arche (7) & 0.98 \\
\cline { 2 - 3 } & Baltimor (5) & 0.99 \\
\cline { 2 - 3 } & CampRemy (7) & 0.99 \\
\cline { 2 - 3 } & Cockpit (5) & 0.98 \\
\cline { 2 - 3 } & Fl. Aurore (5) & 0.99 \\
\cline { 2 - 3 } & Hynoprecia (7) & 0.98 \\
\cline { 2 - 3 } & Isengrain (7) & 0.99 \\
\cline { 2 - 3 } & Oratorio (7) & 0.99 \\
\cline { 2 - 3 } & Recital (7) & 0.90 \\
\cline { 2 - 3 } & Renan (7) & 0.98 \\
\cline { 2 - 3 } & Rumba (7) & 0.95 \\
\cline { 2 - 3 } & Soissons (12) & 0.99 \\
\cline { 2 - 3 } & Tremie (5) & 0.99 \\
\cline { 2 - 3 } & & \\
\cline { 2 - 3 } & & \\
& &
\end{tabular}

leaf for use. We therefore decided to use below only the SPAD readings of the second leaf, L2. Since our objective was to replace NNI by a convenient tool for potential users, this highly 


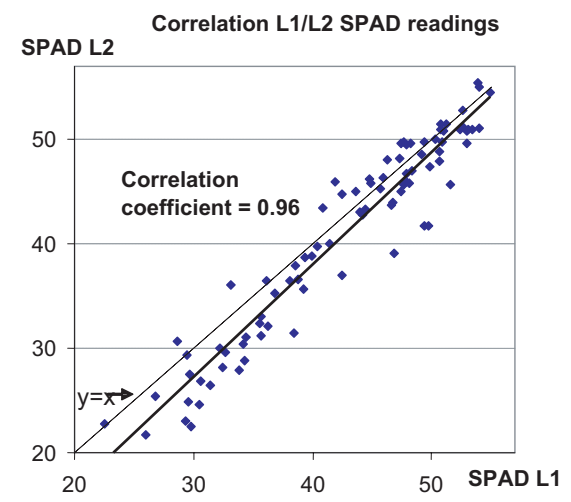

Figure 1. Relationship between SPAD readings from the flag leaf (SPAD L1) and the second leaf (SPAD L2), for 13 cultivars and 3 years. The correlation was significant $(P \leq 0.01)$.

significant correlation enabled us to simplify the experimental work by measuring SPAD values from only one leaf.

\subsection{Relationship between NNI and SPAD}

\subsubsection{Relationships between NNI and SPAD readings}

Taking into account all the available data from the first three experiments, there was a positive exponential relationship between NNI and SPAD readings on L2 at flowering, with a coefficient of determination, $\mathrm{R}^{2}$, of 0.73 (Fig. 2a). We found no references to compare this relationship with other research workers' results. The close relationship between SPAD measurements, taken on a leaf, and NNI, based on whole-plant N content, seemed consistent with the positive correlation observed between SPAD measurements and whole-plant $\mathrm{N}$ content for corn at the 10-leaf growth stage by Wood et al. (1992). Two hypotheses could explain the curvilinear form of the relationship, which was also described by Wood et al. (1992) and Dwyer et al. (1995). Firstly, the discrepancy caused by the fact that SPAD readings were taken from one leaf, whereas NNI was representing whole-plant N, could explain it. Secondly, Wood et al. (1992) and Dwyer et al. (1995) suggested that it could be due to the fact that corn leaf tissue usually only contains $2-3 \%$ of the $\mathrm{N}$ as nitrate and that most of the extra $\mathrm{N}$ is stored in the stalk as nitrate, which seems to be true for all cereals except rice (Takebe and Yoneyama, 1989). This is why the curvilinear response of SPAD to N content could be linked to the increasing total $\mathrm{N}$ in the nitrate form, not detected by chlorophyll meters, at high leaf N levels (Dwyer et al., 1995).

Analyzing the year and cultivar effects on this relationship, there was a highly significant difference in the estimate of NNI between the general model and the individual yearly models, on one hand, $\left(F_{82}^{4}=5.1167, P\right.$ below $10^{-4}$, Fig. 2b) and between the general model and the individual genotypic models, on the other $\left(F_{64}^{24}=5.4366, P\right.$ below $10^{-4}$, Fig. 2c). The specific models were better than the general one with a RMSE general model $_{\text {of }} 0.15$, a RMSE $E_{\text {cultivar }}$ of 0.08 and a RMSE $E_{\text {year }}$ of 0.13 . The significant varietal effect was consistent with the conclusions of Bavec and Bavec (2001) who showed that different cultivars had different SPAD measurements, and Peng et al. (1993) who linked these varietal SPAD measurement differences with the differences in specific leaf weight and lamina thickness among cultivars. The year effect has not been specifically proven in the literature, but it supported Schepers' conclusions (Schepers et al., 1992) showing the effect of cultural practices. The effects of weather on nitrogen dynamics are well known (Gate, 1995).

In the following, we decided to calculate the RMSEP of the general model and not of the individual genotypic or yearly models, even if there was a varietal and a year effect: in fact, we kept in mind that we wanted to build a relationship that would be satisfactory whatever the cultivar or the year. The general model appeared to give too imprecise predictions, with a RMSEP of 0.17 and a RRMSEP of $25.9 \%$, to be used by potential users.

\subsubsection{Relationship between NNI and SPAD index}

There was a positive exponential relationship between the NNI and the SPAD index (Fig. 3a) with a $\mathrm{R}^{2}$ of 0.87 - better than that of the preceding SPAD/NNI relationship and a better simulation error $(\mathrm{RMSE}=0.11)$. Such a good relationship was also found by Vouillot et al. (1998) but its equation was not given in their paper, which limited the comparison with our case. Debaeke et al. (2006) studied this relationship but their results were only partly in agreement with ours: they identified an exponential relationship between the SPAD index and the NNI during stem elongation but they found a linear SPAD index/NNI relationship at flowering. Considering that their $\mathrm{R}^{2}$ were lower than ours and as a curvilinear form was justified (see the preceding paragraph), we kept the exponential form, which also gave a better distribution of the residuals. The difference in behavior could also be due to the different species, durum wheat in Debaeke et al. (ibid), compared with bread wheat in our case.

As before, we checked the effect of the cultivar and the year. There was no longer any significant difference in the estimated NNI between the general model and the individual genotypic models $\left(F_{64}^{24}=0.6972, P\right.$ greater than 0.05$)$. In fact, Schepers et al. (1992) showed that the SPAD readings reached a plateau at high $\mathrm{N}$ rates, dependent on the cultivar, because of the leaf varietal characteristics discussed above. Defining a SPAD index by dividing SPAD measurements by the estimated value of this plateau was thus effective in removing the varietal effect. However, this index did not remove the year effect: there was still a significant difference between the general model and the individual yearly models $\left(F_{82}^{4}=8.7832\right.$, $P$ below $10^{-4}$ ) even though the year effect was less than in the case of the SPAD/INN relationship (Fig. 3b). The yearly model had a lower simulation error than the general one, since the RMSE $E_{\text {year }}$ was 0.09 . This year effect could be linked with specific weather factors that limited the $\mathrm{N}$ status of the crop and affected the thickness of the leaves.

As explained previously, we decided to calculate the RMSEP of the general model and not of the yearly models, because we wanted to build a relationship that could be used in 

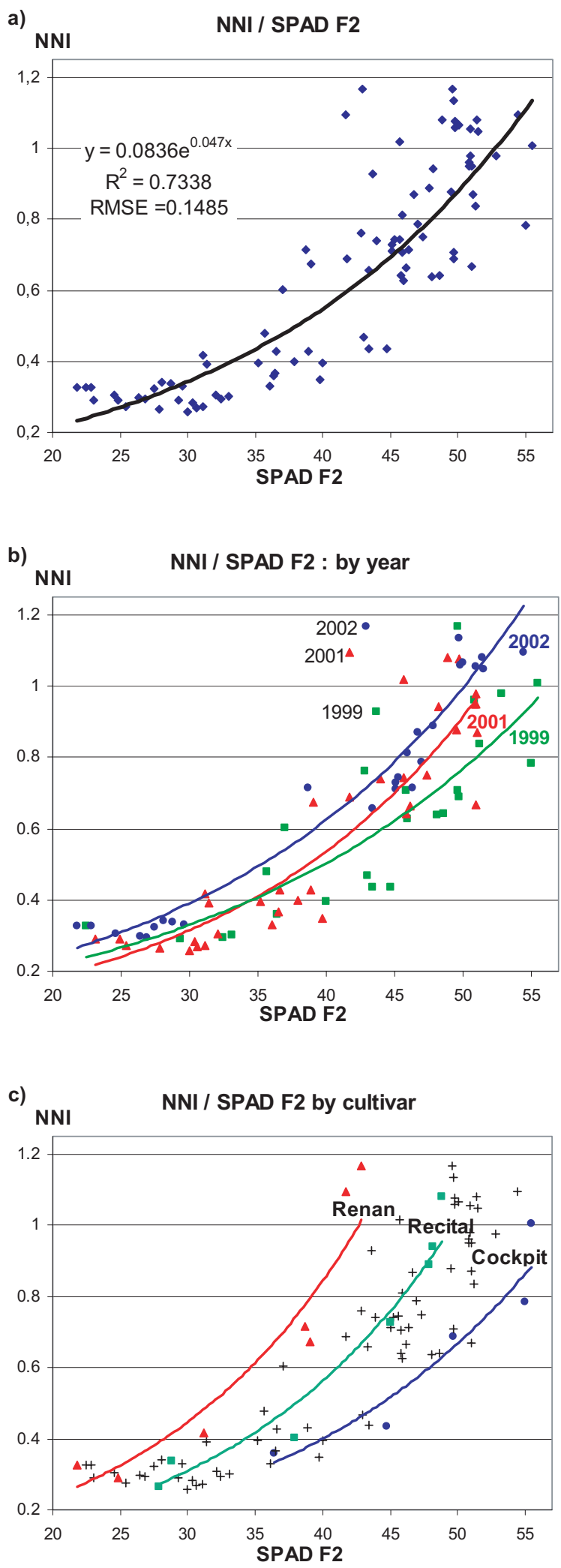

Figure 2. Positive relationship between SPAD L2 measurements and Nitrogen Nutrition Index (NNI), for 13 cultivars and 3 years (a). (b) illustrates the year effect and (c) illustrates the varietal effect. RMSE: Root Mean Square Error.

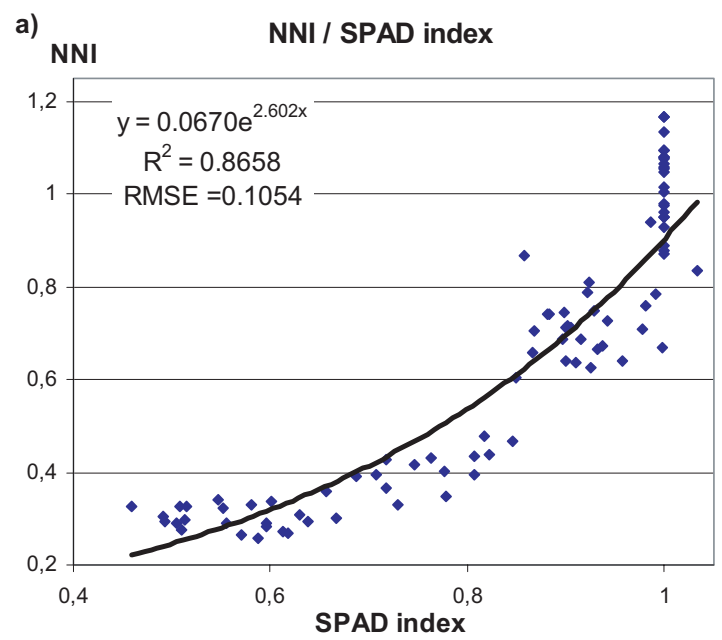

b) NNI / SPAD index: by year

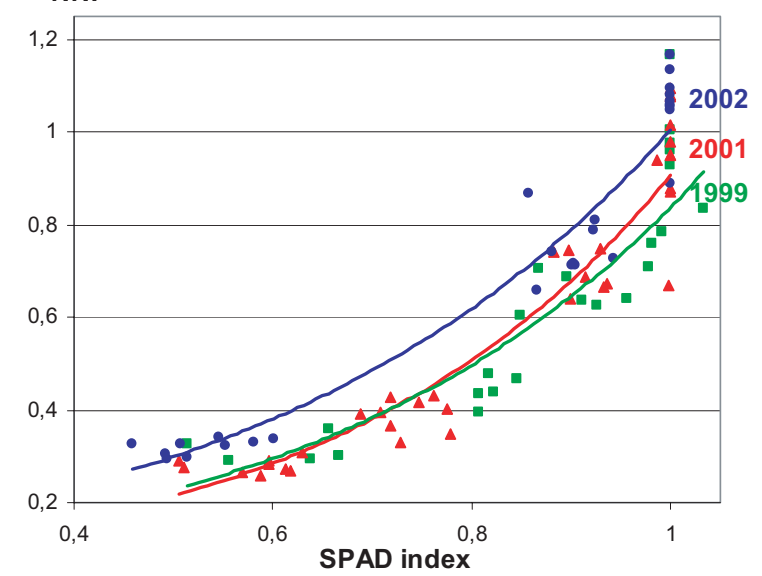

Figure 3. Positive relationship between SPAD index and Nitrogen Nutrition Index (NNI), for 13 cultivars and 3 years (a). (c) illustrates the year effect. RMSE: Root Mean Square Error.

any year. The predictive quality of the general model was quite satisfactory: the model appeared to give quite accurate predictions, with a RMSEP of 0.12 and a RRMSEP of $18.6 \%$. The predictive quality was thus improved by the use of the SPAD index rather than the actual SPAD readings.

Moreover, we showed that if we excluded the data for SPAD indexes of 1 or more, we improved the relationship even further. We established the following relationship: $N N I=$ 0.0847. $e^{2.239 . S P A D i n d e x}$ if the SPAD index is below 1 with a $\mathrm{R}^{2}$ of 0.89, a RMSE of 0.079, a RMSEP of 0.093 and a RRMSEP of $14.5 \%$ with no bias. In fact, the way the index was devised means that SPAD indexes of 1 or more correspond to non-limiting $\mathrm{N}$ situations, whatever their NNI value. For these situations, it was not worthwhile to check the correspondence with NNI. This was consistent with the fact that potential users would be primarily interested in detecting deficiency situations. Furthermore, as discussed above, it was shown that SPAD readings tended to reach a plateau at high $\mathrm{N}$ levels that 


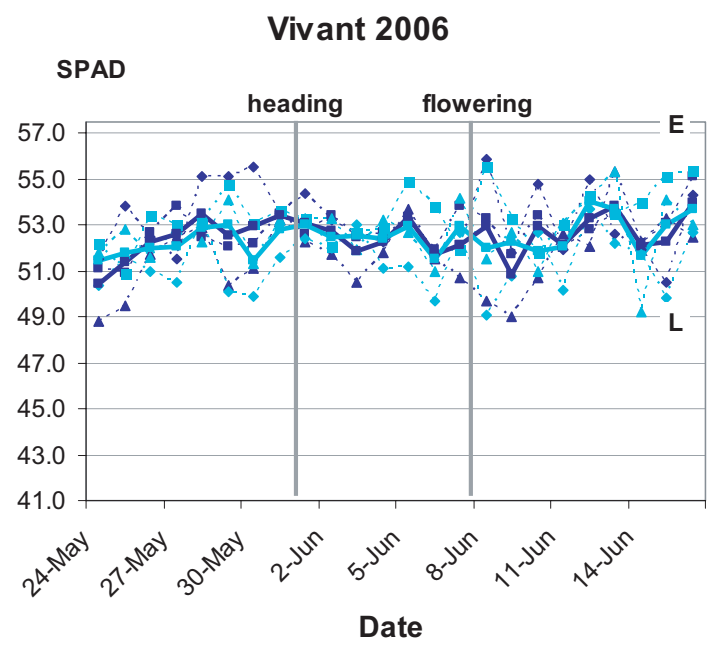

Figure 4. An example of change in time-course of SPAD readings around flowering, for the cultivar Vivant in 2006, grown with 2 fertilization strategies ( $\mathrm{E}$ and $\mathrm{L}$ ). The dotted lines represent the values for each block; the bold ones represent the average value for the fertilization strategy.

weakened the relationships between SPAD readings and $\mathrm{N}$ content (Dwyer et al., 1995). This is why it could be better to use the SPAD index only for values below 1 . Finally, the SPAD index seemed to be able to replace NNI measurements to assess $\mathrm{N}$ deficiencies of a crop but the experiments which allowed us to build the SPAD index/NNI relationship were done at only one location, and thus need to be tested in various other locations. From an operational point of view, the SPAD index would not be hard to measure for our potential users. In fact, they are used to having two crop management systems, usually an intensive one, supposed to be non-limiting, and sometimes a more extensive one (Luciani, 2004). Thus, the intensive crop management could be used as a reference for a well-fertilized plot to very easily calculate the SPAD index.

\subsection{Time span of SPAD measurement around flowering}

Examples of SPAD readings taken around flowering are shown in Figure 4. Although they vary from one block to another as shown by the dotted lines, the effect of the fertilization strategy was visible on SPAD readings (those from E strategy were higher than from L strategy), and on the beginning of senescence, after flowering.

To statistically study the monitoring of SPAD around flowering, we simplified the general model (model 1) to keep only the significant effects. The resulting analysis of variance model satisfactorily fitted the SPAD observations, as the $R^{2}$ was 0.80 (Tab. V). Each main effect was highly significant and so were the following interactions: cultivar.DATE, DATE.year, cultivar.year, cultivar.rep, rep.N technique, $\mathrm{N}$ technique.year, cultivar.DATE.year, cultivar.rep. $\mathrm{N}$ technique, cultivar.N technique.year, rep.N technique.year and cultivar.rep. $\mathrm{N}$ technique.year. These interactions were hard to interpret, as the experiments were homogeneous. Nevertheless, they were of importance: removing the interactions from the model made the $\mathrm{R}^{2}$ fall to 0.42 . The importance of these interactions could mean that some explanatory factors for SPAD variability had not been taken into account, in spite of the good $\mathrm{R}^{2}$. They could be weather effects on SPAD measurements: although such effects, like water deficit, on photosynthesis and chlorophyll content have been studied (e.g. Schepers et al., 1996; Ceccato et al., 2001), we did not know exactly how or how quickly SPAD could react to daily changes in temperature, precipitation or global radiation.

Because we were interested in cultivar and year effects for operational reasons and because both effects were significant, we compared the DATE means by cultivar and by year (Tab. VI). Except for Caphorn in 2006, the SPAD measurements taken over the whole time span were not significantly different from those taken at flowering. For Caphorn in 2006, the measurements taken 5 and 7 days after flowering were significantly different from the flowering SPAD readings, which meant that the SPAD readings were similar to the flowering SPAD measurements only from 9 days before flowering to 4 days after.

Even if we reduced the time span to the shortest one obtained for all cultivars and years, it appeared that this time span was wide, mostly before flowering. Actually, SPAD measurements could be made from 9 days before flowering to 4 days after flowering. Asymmetry around flowering could be linked to leaf senescence. As the wheat approached maturity, the leaves began to lose chlorophyll and to transfer nitrogen to developing kernels. As shown by Adamsen et al. (1999), this process causes a change in color which was detected by SPAD readings. The authors did not define the exact beginning of color change due to senescence, so it was difficult to compare our results and see if a color change could appear as early as 5 days after flowering. However, this senescence could be amplified by diseases which affect leaf color, by weather factors or N management (Adamsen et al., 1999). Consequently, measuring SPAD after flowering seemed hazardous. However, the time span before flowering was very interesting in relation to users' practices. We previously noticed that the potential users usually visited their trials at heading. We also noticed that, because of the range of earliness in a cultivar trial, the time span for heading could last several days. In 2005, there were 13 days between heading of Cezanne, the earliest cultivar, on May 16, and of Vivant, the latest one, on May 30, whereas in 2006 there were 11 days (May 21 for Cezanne cf. June 1 for Vivant). Finally, as heading and flowering were usually separated by 8 to 10 days ( 145 degree days separate heading from flowering according to Gate, 1995), taking SPAD measurements and recording of heading could be done at the same time by juggling with the differences in earliness and by using the proven flexibility of SPAD readings before flowering. It would be interesting to do the same study using the SPAD index. Because the experiments we used did not include intensive plots that should have been taken as a SPAD reference, we were not able to create this index. However, it might have been useful in regard to a cultivar effect that is significant in our SPAD model: our statistical comparison of means could 
Table V. Significant effects of the date of measurement (DATE), cultivar, year, fertilization technique (N technique) and replication (rep) on SPAD measurements, results of linear model (1) ( $\mathrm{df}=$ degree of freedom).

\begin{tabular}{|c|c|c|c|c|c|}
\hline \multicolumn{6}{|c|}{ Sum of squares (SS) } \\
\hline Source & df & (type III) & SS/df & F value & $\operatorname{Pr}>\mathbf{F}$ \\
\hline DATE & 19 & 98.90 & 5.21 & 4.07 & $<.0001$ \\
\hline cultivar & 2 & 34.99 & 17.50 & 13.67 & $<.0001$ \\
\hline N Technique & 1 & 94.57 & 94.57 & 73.88 & $<.0001$ \\
\hline rep & 2 & 25.12 & 12.56 & 9.81 & $<.0001$ \\
\hline year & 1 & 276.32 & 276.32 & 215.87 & $<.0001$ \\
\hline cultivar $*$ DATE & 35 & 148.14 & 4.23 & 3.31 & $<.0001$ \\
\hline DATE * year & 7 & 25.83 & 3.69 & 2.88 & 0.0062 \\
\hline cultivar * year & 2 & 118.76 & 59.38 & 46.39 & $<.0001$ \\
\hline cultivar * rep & 4 & 20.52 & 5.13 & 4.01 & 0.0035 \\
\hline rep $* \mathrm{~N}$ Technique & 2 & 10.83 & 5.41 & 4.23 & 0.0154 \\
\hline N Technique $*$ year & 1 & 17.66 & 17.66 & 13.80 & 0.0002 \\
\hline cultivar $*$ DATE $*$ year & 3 & 10.83 & 3.61 & 2.82 & 0.0391 \\
\hline cultivar $*$ rep $* \mathrm{~N}$ Technique & 4 & 15.12 & 3.78 & 2.95 & 0.0203 \\
\hline cultivar $* \mathrm{~N}$ Technique $*$ year & 2 & 20.99 & 10.49 & 8.20 & 0.0003 \\
\hline rep $*$ N Technique $*$ year & 4 & 25.03 & 6.26 & 4.89 & 0.0008 \\
\hline cultivar $*$ rep $* N$ Technique $*$ year & 8 & 43.35 & 5.42 & 4.23 & $<.0001$ \\
\hline TOTAL $\mathbf{R}^{2}$ & \multicolumn{5}{|c|}{$\mathbf{0 . 7 9}(P<0.001)$} \\
\hline SPAD mean & \multicolumn{5}{|c|}{52.70} \\
\hline Root MSE & \multicolumn{5}{|c|}{1.13} \\
\hline
\end{tabular}

Table VI. Results of the comparison of means to determine the minimum time span during which SPAD measurements could be made.

\begin{tabular}{|c|c|c|c|c|}
\hline Year & Cultivar & $\begin{array}{l}\text { Measured } \\
\text { time span } \\
\text { from DATE “0” SPAD }\end{array}$ & $\begin{array}{l}\text { Dates for which SPAD } \\
\text { measurements were different } \\
\text { same as the SPAD at DATE "0" }\end{array}$ & $\begin{array}{l}\text { Time span in which SPAD } \\
\text { measurements were statistically the }\end{array}$ \\
\hline \multirow[t]{3}{*}{2005} & Cezanne & $-9 / 9$ & - & $-9 / 9$ \\
\hline & Cap Horn & $-10 / 9$ & - & $-10 / 9$ \\
\hline & Vivant & $-9 / 9$ & - & $-9 / 9$ \\
\hline \multirow[t]{3}{*}{2006} & Cezanne & $-9 / 8$ & - & $-9 / 8$ \\
\hline & Cap Horn & $-9 / 8$ & DATE “5”, DATE “7” & $-9 / 4$ \\
\hline & Vivant & $-9 / 8$ & - & $-9 / 8$ \\
\hline
\end{tabular}

have been more powerful without it. And here again, it would be interesting to test this result at other locations and in other years, the SPAD measurements having been monitored every day only in 2006.

\section{CONCLUSION}

From our experiments, we showed that the SPAD index can substitute NNI measurements to assess $\mathrm{N}$ deficiencies. In fact, although our results proved that there was still a year effect on the relationship between the SPAD index and NNI, the general model gave a prediction accurate enough to detect $\mathrm{N}$ deficiencies correctly. This conclusion should be checked at other locations. Moreover, we have given further information to potential users to make these SPAD measurements feasible and compatible with their practices. Firstly, we showed that measurements on L1 or L2 were highly correlated, which would permit the users to restrict their measurements to one leaf. Then we studied how we could give the users more flexibility to take the SPAD measurements around flowering. We showed that it is possible to combine the measurements of SPAD with the recording of heading, which the users are used to doing, thanks to the wide range of earliness that could be found in cultivar trials. This result could thus give the users additional leeway in their experimental work. Here again, it would be interesting to check the validity of this result at other locations and in other years. Finally, this study was based on the 
practical constraints of potential users wishing to assess their cultivars' response to $\mathrm{N}$ deficiency. This original starting point led us to define research questions which were original in their formulation and in the way we treated them. It also opened up new areas of possible work on the accuracy of SPAD compared with the NNI. Substituting the NNI by the SPAD index in some of our partners' trials for the next season would allow us to test its validity on a wider scale, to improve our NNI/ SPAD index model and get further information about the practical use of SPAD. It would also be interesting to study the behavior of new devices such as active sensors to evaluate chlorophyll status, as these devices give results which correlate well with SPAD readings and could be even faster and easier to use.

Acknowledgements: We are grateful for the support from the FSOV (French fund for plant breeding). The experiments were conducted by $\mathrm{J}$. Troizier, director of the Experimental Unit of Versailles-Grignon, and his technical staff. A. Barbottin and C. Bouchard monitored the 1999/2001/2002 experiments and C. Bouchard gave us valuable help to monitor SPAD readings in 2005 and 2006. Thanks to C. Naud, A. Gauffreteau and D. Makowski who spent time to discuss our statistical choices. C. Godin and M.N. Mistou (GEVES), M.H. Bernicot (Arvalis Institut du Végétal), P. Lonnet, J.P. VanSuyt and T. Demarquet (Florimond Desprez), E. Margalé, M. Meausoonne, S. Vergez and J.P. Monnier (Serasem), J.B. Beaufume and G. Stagnaro (Nickerson), and P. Senellart and O. Leblanc (C.C. Benoist) gave us their time to describe their experimental practices and constraints. We also thank A. Scaife for correcting the English language. We are grateful to all of them for their help.

\section{REFERENCES}

Adamsen F.J., Pinter P.J. Jr., Barnes E.M., LaMorte R.L., Wall G.W., Leavitt S.W., Kimball B.A. (1999) Measuring wheat senescence with a digital camera, Crop Sci. 39, 719-724.

Anjana, Umar S., Iqbal M. (2007) Nitrate accumulation in plants, factors affecting the process, and human health implication, Agron. Sustain. Dev. 27, 45-57.

Barbottin A., Lecomte C., Bouchard C., Jeuffroy M.H. (2005) Nitrogen Remobilization during Grain Filling in Wheat: Genotypic and Environmental Effects, Crop Sci. 45, 1141-1150.

Bavec F., Bavec M. (2001) Chlorophyll meter readings of winter wheat cultivars and grain yield prediction, Commun. Soil Sci. Plan. 32, 2709-2719.

Blackmer T.M., Schepers J.S. (1995) Use of a Chlorophyll Meter to Monitor Nitrogen Status and Schedule Fertigation for Corn, J. Prod. Agr. 8, 56-60.

Brancourt-Hulmel M., Lecomte C., Meynard J.M. (1999) A Diagnosis of Yield-Limiting Factors on Probe Genotypes for Characterizing Environments in Winter Wheat Trials, Crop Sci. 39, 1798-1808.

Ceccato P., Flasse S., Tarantola S., Jacquemoud S., Gregoire J.M. (2001) Detecting vegetation leaf water content using reflectance in the optical domain, Remote Sens. Environ. 77, 22-33.

Debaeke P., Rouet P., Justes E. (2006) Relationship between the normalized SPAD index and the nitrogen nutrition index: application to Durum Wheat, J. Plant Nutr. 29, 75-92.

Dwyer L.M., Anderson A.M., Ma B.L., Stewart D.W., Tollenaar M., Gregorich E. (1995) Quantifying the nonlinearity in chlorophyll meter response to corn leaf nitrogen concentration, Can. J. Plant Sci. $75,179-182$.
Fox R.H., Piekielek W.P., Macneal K.M. (1994) Using a chlorophyll meter to predict nitrogen fertilizer needs of winter wheat, Commun. Soil Sci. 25, 171-181.

Gate P. (1995) Écophysiologie du Blé, Lavoisier, Tec \& Doc, Paris.

Jeuffroy M.H., Bouchard C. (1999) Intensity and Duration of Nitrogen Deficiency on Wheat Grain Number, Crop Sci. 39, 1385-1393.

Justes E., Jeuffroy M.H., Mary B. (1997) Wheat, Barley and Durum Wheat, in: Lemaire G. (Ed.), Diagnosis of the Nitrogen Status in Crops, Vol. 4. , Springer, pp. 73-92.

Justes E., Mary B., Meynard J.-M., Machet J.M., Thelier Huche L. (1994) Determination of a critical nitrogen dilution curve for winter wheat crops, Ann. Bot. 74, 397-407.

Lemaire G., Gastal F. (1997) N uptake and Distribution in Plant Canopies, in: Lemaire G. (Ed.), Diagnosis of the Nitrogen Status in Crops, vol. 1, Springer, pp. 3-43.

Luciani A. (2004) Étude du progrès génétique chez différentes espèces en grandes cultures, Geves.

Machet J.M., Dubrulle P., Louis P. (1990) Azobil: A computer program for fertilizer $\mathrm{N}$ recommendations based on a predictive balance sheet method, Paris.

Martinez D.E., Guiamet J.J. (2004) Distortion of the SPAD 502 chlorophyll meter readings by changes in irradiance and leaf water status, Agronomie 24, 41-46.

Matsunaka T., Watanabe Y., Miyawaki T., Ichikawa N. (1997) Prediction of Grain Protein Content in Winter Wheat through Leaf Color Measurements Using a Chlorophyll Meter, Soil Sci. Plant Nutr. 43, $127-134$.

Peng S., Garcia F.V., Laza R.C., Cassman K.G. (1993) Adjustement for Specific Leaf Weight Improves Chlorophyll Meter's Estimate of Rice Leaf Nitrogen Concentration, Agron. J. 85, 987-990.

Reeves D.W., Mask P.L., Wood C.W., Delaney D.P. (1993) Determination of wheat nitrogen status with a hand-held chlorophyll meter: influence of management practices, J. Plant Nutr. 16, 781-796.

SAS Institute Inc (1999) SAS OnlineDoc ${ }^{\circledR}$ Version 8, SAS Institute Cary, NC.

Schepers J.S., Francis D.D., Vigil M., Below F.E. (1992) Comparison of corn leaf nitrogen concentration and chlorophyll meter readings, Commun. Soil Sci. Plan. 23, 2173-2187.

Schepers J.S., Blackmer T.M., Wilhelm W.W., Resende M. (1996) Transmittance and Reflectance Measurements of Corn Leaves from Plants with Different Nitrogen and Water Supply, J. Plant Physiol. $148,523-529$.

Takebe M., Yoneyama T. (1989) Measurement of Leaf Color Scores and Its Implication to Nitrogen Nutrition of Rice Plants, Jpn Agr. Res. Quaterly 23, 86-93.

van Eeuwijk F.A. (1995) Linear and bilinear models for the analysis of multi-environment, trials: an inventory of models, Euphytica 84, $1-7$.

Varvel G.E., Schepers J.S., Francis D.D. (1997) Ability for In-Season Correction of Nitrogen Deficiency in Corn Using Chlorophyll Meters, Soil Sci. Soc. Am. J. 61, 1233-1239.

Vidal I., Longeri L., Hétier J.M. (1999) Nitrogen uptake and chlorophyll meter measurements in spring wheat, Nutr. Cycl. Agroecosys. 55, $1-6$.

Vouillot M.O., Huet P., Boissard P. (1998) Early detection of N deficiency in a wheat crop using physiological and radiometric methods, Agronomie 18, 117-130.

Wallach D. (2006) Evaluating crop models, in: Wallach D., Makowski D., Jones J. (Eds.), Working with Dynamic Crop Models, pp. 11-50.

Wallach D., Goffinet B. (1987) Mean squared error of prediction in models for studying ecological and agronomic systems, Biometrics 43 , 561-573.

Wood C.W., Reeves D.W., Duffield R.R., Edmisten K.L. (1992) Field chlorophyll measurements for evaluation of corn nitrogen status, J. Plant Nutr. 15, 487-500. 